\title{
Effect of general symptom level, specific adverse events, treatment patterns, and patient characteristics on health-related quality of life in patients with multiple myeloma: results of a European, multicenter cohort study
}

\author{
Karin Jordan • Irina Proskorovsky • Philip Lewis • Jack Ishak • Krista Payne • \\ Noreen Lordan • Charalampia Kyriakou • Cathy D. Williams • Sarah Peters • \\ Faith E. Davies
}

Received: 7 March 2013 / Accepted: 17 September 2013 /Published online: 13 October 2013

(C) The Author(s) 2013. This article is published with open access at Springerlink.com

\begin{abstract}
Purpose Novel multiple myeloma (MM) therapies have increased patient longevity but are often associated with notable symptom burden. This study quantified the effect of general symptom level, specific symptoms, and treatment-related adverse events (AEs) on MM patients' health-related quality of life (HRQoL).
\end{abstract}

\author{
K. Jordan $(\bowtie)$ \\ Department for Hematology/Oncology, Klinik und Poliklinik für \\ Innere Medizin IV, Universitätsklinikum Halle (Saale), \\ Ernst-Grube-Str. 40, Halle 06120, Germany \\ e-mail: karin.jordan@uk-halle.de \\ I. Proskorovsky $\cdot$ J. Ishak \\ Evidera, Saint-Laurent, QC, Canada \\ K. Payne \\ United BioSource Corporation, Dorval, QC, Canada \\ P. Lewis \\ Market Access, Celgene GmbH, Munich, Germany \\ N. Lordan \\ United BioSource Corporation, Lexington, MA, USA \\ C. Kyriakou \\ Department of Hematology, Northwick Park Hospital, North West \\ London NHS Trust, Harrow, UK \\ C. D. Williams \\ Centre for Clinical Hematology, Nottingham University Hospital, \\ Nottingham, UK \\ S. Peters \\ Celgene, Windsor, UK \\ F. E. Davies \\ Royal Marsden Hospital, Surrey, UK
}

Methods The European Organization for Research and Treatment of Cancer (EORTC) generic cancer questionnaire (Quality of Life Questionnaire Core 30) and MM-specific questionnaire (QLQ-MY20) were used in this study to assess patients' HRQoL. Data were collected on sociodemographics, disease and treatment history, and the presence/severity of MM-related symptoms or treatment-related AEs from patients with MM in $11 \mathrm{UK}$ and German centers. Multiple regression analyses were conducted.

Results Of 154 patients (63\% male; mean age, 66.4 years; mean time since diagnosis, 3.7 years; $52 \%$ currently on treatment; and $43 \%$ with $\geq 1$ prior MM therapy), $25,32,31$, and $11 \%$ were severely symptomatic, moderately symptomatic, mildly symptomatic, and asymptomatic, respectively. Fatigue (59\%), bone pain (51\%), sleepiness (36\%), hypoesthesia or paresthesia (33\%), and muscle cramps $(31 \%)$ were most commonly reported. Moderate and severe general symptom levels, bone symptoms, depression, and mental status changes were identified as strong determinants of HRQoL.

Conclusions Severity, type of disease symptoms, and treatmentrelated AEs are important HRQoL determinants in patients with $\mathrm{MM}$, allowing for targeted treatment.

Keywords Adverse events · Health-related quality of life · Multiple myeloma $\cdot$ Symptoms

\section{Introduction}

Multiple myeloma (MM) is the second most prevalent hematologic malignancy, representing $1 \%$ of all cancers, with an increasing incidence due to population longer life expectancy and increasing prevalence due to improved treatments $[1,2]$. 
According to estimates by the European Network of Cancer Registries, there are 21,420 new cases of MM in Europe annually and approximately 15,000 MM-related deaths. At any time, $>77,000$ people in Europe are undergoing treatment for MM [3].

Significant progress has been achieved in the treatment of $\mathrm{MM}$ in recent decades [4, 5]. The use of high-dose chemotherapy with stem cell transplantation (SCT) improved disease-free survival, and has increased overall survival (OS) compared with standard conventional chemotherapy comprising melphalan and prednisone [6]. More recently, the introduction of novel therapeutic agents has improved treatment response rates and progression-free survival of patients with MM [7-16]. Improved OS has also been reported in patients treated with thalidomide, lenalidomide, or bortezomib [4]. However, in many cases there is a distinct symptom burden associated with the increased longevity and longer disease course [17, 18]. The management of patients with MM may be improved by a better understanding of the extent to which patients are affected by general symptom level, specific symptoms, and treatment-related adverse events (AEs) and how this, in turn, impacts health-related quality of life (HRQoL).

This study was conducted to quantify the effect of patients' general symptom level on HRQoL, and to identify specific disease-related symptoms and treatment-related AEs associated with HRQoL over and above the patients' general symptom level.

\section{Methods}

\section{Study design}

This cross-sectional, bi-national, multicenter study enrolled consecutive MM patients presenting for routine care visits at five UK and six German sites. All enrolled patients were required to understand and voluntarily sign an informed consent form. Eligible patients were aged $\geq 18$ years with a current diagnosis of $\mathrm{MM}$ and were representative of one out of four pre-defined study subgroups: asymptomatic, mildly symptomatic, moderately symptomatic, or severely symptomatic. Each study subgroup remained open for enrollment until a quota of 51 patients was reached.

Patients were not eligible for enrollment if they had undergone an autograft transplantation within the past 3 months or if they had received an experimental MM treatment.

The study was approved by the institutional review boards of the participating Centres and conducted according to the Declaration of Helsinki International Conference on Harmonization and the guidelines for Good Clinical Practice. Written informed consent was obtained from all patients before enrollment.

\section{Instruments}

The European Organization for Research and Treatment of Cancer (EORTC) Quality of Life Questionnaire Core 30 (QLQ-C30) and MM module questionnaire (QLQ-MY20) were used to measure patients' HRQoL. These questionnaires have been shown to be reliable and valid measures for detecting differences in the quality of life $(\mathrm{QoL})$ of patients with cancer and specifically in those with MM [19-21]. Differences of 6-17 points in selected scores of the EORTC QLQ-C30 have been found to represent a clinically meaningful change in patients with MM, whereby a 10-point reduction can be interpreted as a moderate effect size [22]. A preliminary study by Williams et al. [23] demonstrated that Physical Functioning, Social Functioning, and Fatigue from QLQC30; and Future Perspective and Disease Symptoms from QLQ-MY20 are important determinants of Global Health Status/QoL. These subscales were, therefore, the main focus of this paper.

\section{Patients' general symptom level}

Each patient's general symptom level was determined using an MM symptoms and AE checklist and classification form. This form was developed in English by five hematologists (Drs Hall, Crotty, Oakervee, Che, and Ashcroft), all experienced in treating patients with MM, and then translated into German and administered by the physician during treatment. Patients with MM were asked to provide a score from 1 to 4 for each of $39 \mathrm{MM}$ symptoms/AEs pre-defined as clinically relevant. The list of symptoms/AEs included bone pain, fracture, fatigue, and motor and sensory neuropathy. Final AE severity categories were assigned based on the average score for each grade of symptom/AE. Based on the severity of the reported AEs and symptoms, patients were assigned to one of four symptom groups: asymptomatic if a patient had no symptoms/AEs; mildly symptomatic if a patient reported $\geq 1$ mild symptom/AE and no moderate or severe symptom/AE; moderately symptomatic if a patient reported $\geq 1$ moderate symptom/AE and no severe symptoms/AEs; and severely symptomatic if a patient reported $\geq 1$ severe symptom/AE.

Data collection

Data on HRQoL (EORTC QLQ-C30 and EORTC QLQMY20) were also collected at a single patient study visit. The QLQ-C30 comprises a Global Health Status/QoL domain, five functional and three symptom domains, and six AE items. The QLQ-MY20 includes scales for Disease Symptoms, Side Effects of Treatment, Future Perspective, and Body Image. Values for each scale range from 0 to 100 . Higher values indicate better HRQoL for the Global Health Status/ QoL, Functional, Future Perspective, and Body Image scales. 
By contrast, higher values indicated a worse HRQoL score for the AE items, symptom domains, Disease Symptoms, and AE scales. Scoring of the QLQ-C30 [24] and QLQ-MY20 [21] scales has been described previously.

The site study staff completed a sociodemographics form and a medical history form based on each participant's medical record. The sociodemographics form included information about age, gender, and nationality of the patients, whereas the medical history form contained data on height, weight, date of MM diagnosis, laboratory tests, presence of lytic bone lesion or pathological fracture at the time of diagnosis, comorbidities, and SCT/MM treatment history. Each line of treatment was classified as containing bortezomib, lenalidomide, thalidomide, alkylating agents, or "other treatments." Current treatment was defined as the regimen received within 30 days of the study visit. Prior treatment was defined as the MM regimen received within the past 12 months and preceding the study visit by $>30$ days.

\section{Statistical analysis}

The associations between symptom level plus individual symptoms/AEs on the one hand and Global Health Status/ QoL, Physical Functioning, Social Functioning, Fatigue, Disease Symptoms, and Future Perspective as dependent outcome variables on the other hand were explored via multiple linear regression analyses. The majority of the symptoms/AEs collected in the study were reported rarely and, as a consequence, different severity levels of AEs included only a few patients. Thus, to allow meaningful analysis, only the presence or absence of the rarely reported symptoms/AEs were considered.

In addition to symptom level and individual symptoms/AEs and their severity, the following variables were considered for the multiple regression analysis: age, gender, nationality, body mass index, duration of disease, beta-2-microglobulin and albumin levels at diagnosis, lytic bone lesion or pathological fracture at diagnosis, number of comorbidities present at the study visit, prior SCT, type and duration of current/prior treatment, number of prior treatments, interaction between type and duration of current/prior treatment, response to last cycle of current treatment, and best response to last cycle of (all) prior treatment(s) combined.

Given the number of potential predictors of interest and patient sample size $(N=154)$, multiple regression models were constructed giving priority to symptom severity group and individual AEs. The following strategy was used to prioritize variables of interest: each of the 39 specific AEs was tested in univariate regression models against the six HRQoL measures; those that were statistically significant $(P<0.10)$ were then tested in a model including the general symptom level. Those found to be significant in this second step were combined in a multivariate model that was then trimmed to exclude items that lost significance. Other potential determinants, like sociodemographics and disease and treatment history variables, found to be significant in univariate analyses were then added to the trimmed multivariate model, which was further reduced by excluding nonsignificant terms.

\section{Results}

Patients disposition and characteristics

The study enrolled 154 patients ( 89 and 65 patients from the UK and Germany, respectively). A total of 39 (25\%) patients enrolled in the study were severely symptomatic, 50 (32\%) were moderately symptomatic, 48 (31\%) were mildly symptomatic, and $17(11 \%)$ were asymptomatic. Average age at enrollment was 66.4 years (interquartile range (IQR), 61.0$74.0)$ and $63 \%$ were male. The majority of patients $(84 \%)$ were of British or German descent. The average time since diagnosis was 3.7 years (IQR, 0.9-5.7). Patients in more severe symptom groups showed a trend towards a higher number of comorbidities (Table 1) and were more likely to be on a current MM regimen (Table 2).

\section{Symptoms}

The most commonly reported AEs included fatigue (59\%), bone pain $(51 \%)$, sleepiness (36\%), hypoesthesia or paresthesia (33\%), muscle cramps (31\%), constipation (28\%), peripheral edema (26\%), and insomnia (25\%). Dizziness (19\%), blurred vision (19\%), dehydration or thirstiness $(18 \%)$, infection (16\%), tremor (15\%), sensory (painful) neuropathy (15\%), headache (14\%), depression (14\%), and nausea/vomiting (12\%) were reported less frequently. Other AEs and disease symptoms were reported by $<10 \%$ of patients (Fig. 1).

\section{Treatment history}

Overall, 80 patients (52\%) were on treatment in the month prior to the study visit. Of these, 37 (46\%) patients received regimens based on bortezomib, 17 (21\%) patients received lenalidomide-containing regimens, 15 (19\%) patients had treatments based on thalidomide, $8(10 \%)$ patients received alkylating agents, and $3(4 \%)$ patients had other types of treatment. More than half of all patients $(57 \%)$ had no prior treatment, $32 \%$ had received 1 prior treatment in the past 12 months, and the remaining $11 \%$ had received $\geq 2$ prior therapies within 12 months of the study visit (Table 2).

HRQoL by general symptom severity level

The overall mean \pm standard deviation Global Health Status/ QoL score was $60.1 \pm 25.5$, with the IQR between 41.7 and 
Table 1 Patient baseline demographics

\begin{tabular}{llllll}
\hline Variable & $\begin{array}{l}\text { Overall } \\
(N=154)\end{array}$ & $\begin{array}{l}\text { Asymptomatic } \\
(n=17)\end{array}$ & $\begin{array}{l}\text { Mildly symptomatic } \\
(n=48)\end{array}$ & $\begin{array}{l}\text { Moderately symptomatic } \\
(n=50)\end{array}$ & $\begin{array}{l}\text { Severely symptomatic } \\
(n=39)\end{array}$ \\
\hline $\begin{array}{l}\text { Male }(n(\%)) \\
\text { Age (mean } \pm \text { SD, years) }\end{array}$ & $97(63)$ & $12(71)$ & $31(65)$ & $27(54)$ & $27(69)$ \\
Nationality $(n(\%))$ & $66.4 \pm 10.0$ & $66.9 \pm 11.0$ & $66.0 \pm 8.9$ & $67.4 \pm 10.3$ & $65.5 \pm 10.8$ \\
$\quad$ British & $73(47)$ & $5(29)$ & $27(56)$ & $29(58)$ & $12(31)$ \\
$\quad \begin{array}{l}\text { German } \\
\text { Other }\end{array}$ & $56(36)$ & $12(71)$ & $11(23)$ & $15(30)$ & $18(46)$ \\
Comorbidities present at the time of the visit $(n(\%))$ & & $10(21)$ & $6(12)$ & $9(23)$ \\
$\quad$ None & $49(32)$ & $6(35)$ & $17(35)$ & $19(38)$ & $7(18)$ \\
1 & $44(29)$ & $6(35)$ & $15(31)$ & $5(10)$ & $6(15)$ \\
2 & $24(16)$ & $5(29)$ & $6(13)$ & $9(18)$ & $8(21)$ \\
$\geq 3$ & $37(24)$ & 0 & $10(21)$ & $4.2 \pm 3.7$ & $18(46)$ \\
Duration of MM (mean \pm SD, years) & $3.7 \pm 3.7$ & $3.3 \pm 3.3$ & $3.6 \pm 3.9$ & & $3.6 \pm 3.4$ \\
\hline
\end{tabular}

$M M$ multiple myeloma, $S D$ standard deviation

83.3. Physical Functioning (mean, 68.7; IQR, 53.3-93.3) and Social Functioning (mean, 63.9; IQR, 33.3-100) scores were slightly higher than Future Perspective scores (mean, 59.9; IQR, 33.3-77.8). Higher symptom severity levels were associated with greater impairments in HRQoL; $\geq 6$-point difference in average score between each level was observed for Global
Health Status/QoL, Physical Functioning, and Social Functioning (Fig. 2). The reported mean score for Future Perspective was nearly 20 points higher for asymptomatic and mildly symptomatic patients, compared with patients in the moderately and severely symptomatic groups. Fatigue scores were highest among patients in the severely symptomatic group

Table 2 Treatment history

\begin{tabular}{|c|c|c|c|c|c|}
\hline Variable & $\begin{array}{l}\text { Overall } \\
(N=154)\end{array}$ & $\begin{array}{l}\text { Asymptomatic } \\
(n=17)\end{array}$ & $\begin{array}{l}\text { Mildly } \\
\text { symptomatic } \\
(n=48)\end{array}$ & $\begin{array}{l}\text { Moderately } \\
\text { symptomatic } \\
(n=50)\end{array}$ & $\begin{array}{l}\text { Severely } \\
\text { symptomatic } \\
(n=39)\end{array}$ \\
\hline Currently (past 30 days) receiving MM therapy $(n(\%))$ & $80(52)$ & $7(41)$ & $19(40)$ & $33(66)$ & $21(54)$ \\
\hline \multicolumn{6}{|l|}{ Type of current MM therapy $(n(\%))$} \\
\hline Bortezomib containing & $37(46)$ & $3(43)$ & $7(37)$ & $19(58)$ & $8(38)$ \\
\hline Lenalidomide containing & $17(21)$ & $3(43)$ & $4(21)$ & $6(18)$ & $4(19)$ \\
\hline Thalidomide containing & $15(19)$ & $1(14)$ & $6(32)$ & $4(12)$ & $4(19)$ \\
\hline Alkylating agents containing & $8(10)$ & 0 & $2(11)$ & $4(12)$ & $2(10)$ \\
\hline Other & $3(4)$ & 0 & 0 & 0 & $3(14)$ \\
\hline \multicolumn{6}{|l|}{ Number of prior MM therapies in the past 12 months $(n(\%))$} \\
\hline 0 & $88(57)$ & $11(65)$ & $29(60)$ & $28(56)$ & $20(51)$ \\
\hline 1 & $49(32)$ & $3(18)$ & $15(31)$ & $18(36)$ & $13(33)$ \\
\hline 2 & $13(8)$ & $3(18)$ & $3(6)$ & $3(6)$ & $4(10)$ \\
\hline$\geq 3$ & $4(3)$ & 0 & $1(2)$ & $1(2)$ & $2(5)$ \\
\hline \multicolumn{6}{|l|}{ Type of prior MM therapy in the past 12 months $(n(\%))$} \\
\hline Bortezomib containing & $28(18)$ & $5(29)$ & $4(8)$ & $9(18)$ & $10(26)$ \\
\hline Lenalidomide containing & $3(2)$ & 0 & $1(2)$ & $2(4)$ & 0 \\
\hline Thalidomide containing & $31(20)$ & $2(12)$ & $12(25)$ & $9(18)$ & $8(21)$ \\
\hline Alkylating agents containing & $17(11)$ & $2(12)$ & $5(10)$ & $5(10)$ & $5(13)$ \\
\hline Other & $6(4)$ & 0 & $2(4)$ & $1(2)$ & $3(8)$ \\
\hline
\end{tabular}

$M M$ multiple myeloma 
Fig. 1 Frequently reported multiple myeloma symptoms and adverse events. Collapse of vertebral body, bone fracture, abdominal pain, petechiae/ purpura, gastrointestinal bleeding, upper respiratory tract infection, pneumonia, fever, febrile neutropenia, diarrhea, asthenia or tiredness, anorexia, dyspepsia, motor neuropathy, carpal tunnel syndrome, syncope, states of confusion, mental status changes, cerebrovascular accident, rash, deep-vein thrombosis, hypotension, and renal failure were reported by $<10 \%$ of patients

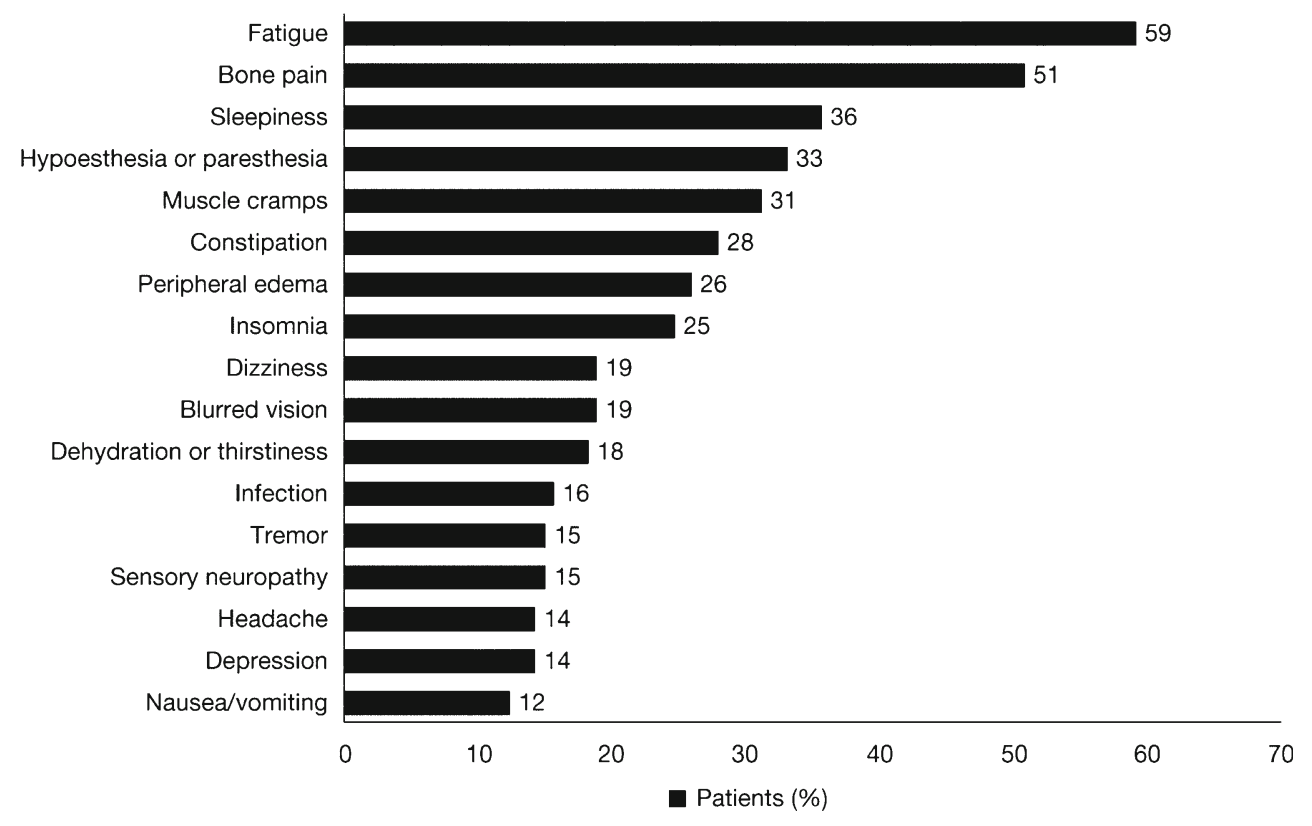

(mean, 58.1; IQR 44.4-77.8), whereas patients in the asymptomatic group had a mean of 15.7 (IQR, 0-33.3) (Fig. 3).

Results of multiple regression analyses

\section{Global Health Status/QoL}

Patients with severe and moderate symptoms had on average 19 and 12 points lower QoL scores, respectively, compared with asymptomatic patients. Patients with severe bone pain had an additional 21-point reduction in score compared with those who had none or only mild or moderate bone pain. Depression and moderate fatigue had similar effects on Global Health Status/QoL scores and each was associated with an 11-point reduction in score. Each additional year with MM was associated with a QoL reduction of 1 score point. Receiving any type of $\mathrm{MM}$ treatment within the past 30 days was also associated with a 9.5-point reduction in the Global Health Status/QoL score (Table 3).
Fig. 2 Distribution of healthrelated quality of life by symptom level: Global Health Status/ Quality of Life $(Q o L)$, Physical Functioning, Social Functioning, and Future Perspective. Higher scores are "better"; error bars represent standard deviation

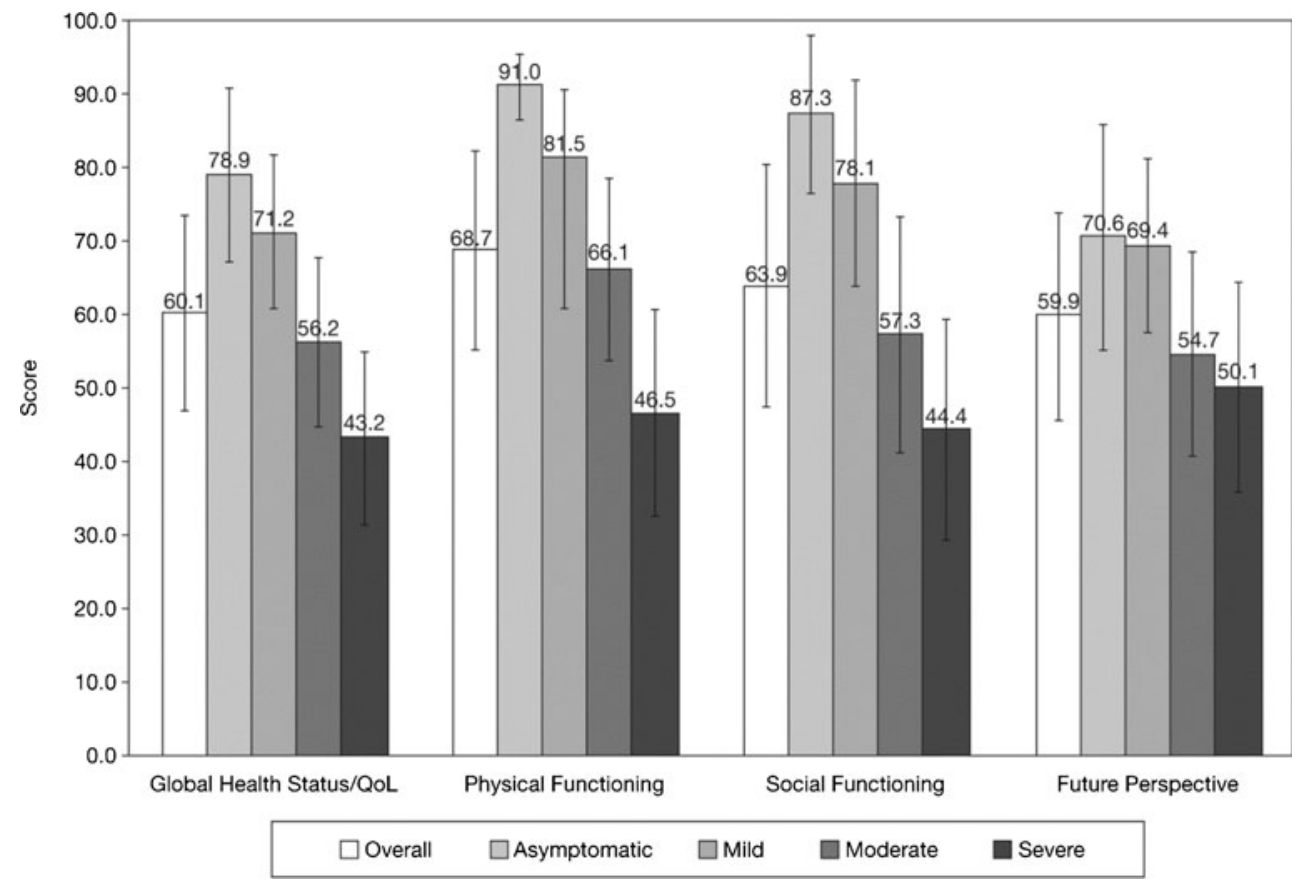


Fig. 3 Distribution of healthrelated quality of life by symptom level: Fatigue and Disease Symptoms. Lower scores are "better"; error bars represent standard deviation

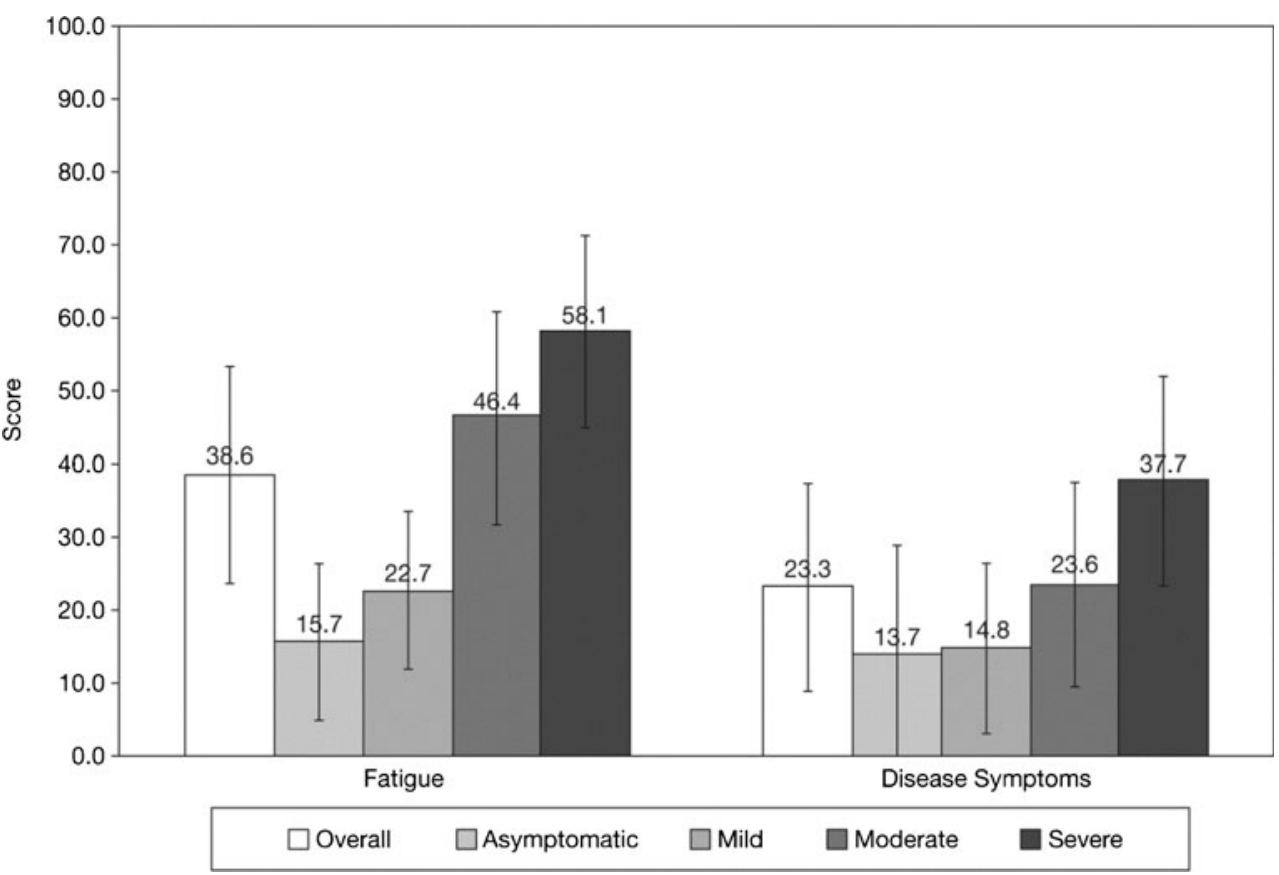

\section{Physical functioning}

General severity level was a strong predictor of Physical Functioning; patients with severe, moderate, and mild symptom levels (vs. none) experienced a 24-, 13- and 11-point reduction in their Physical Functioning score, respectively. In addition to the overall level of severe and moderate bone pain, the presence of fracture, moderate fatigue, and moderate/severe infection were all associated with $\geq 10$-point decrease in Physical Functioning score. Longer prior treatment with bortezomib also reduced Physical Functioning levels. Patients who were treated with bortezomib-containing regimens for 111 days (approximately 5.5 cycles of 21-days) had on average a 10-point lower Physical Functioning score compared with patients who had not received prior bortezomib. Thalidomide and alkylating agent-containing treatments had no significant effect on Physical Functioning. Prior lenalidomide and prior other treatments were not tried in the regression analyses because of the low number of patients with a history of these treatments ( 3 and 6 , respectively). British and younger patients tended to report better Physical Functioning (Table 3).

\section{Social functioning}

Social Functioning was significantly affected by general symptom level. Patients with severe, moderate, and mild symptoms had Social Functioning scores that were on average 34, 24, and 6 points lower, respectively, compared with asymptomatic patients. Fracture, dizziness, and changes in mental status were also associated with a significant reduction in the Social Functioning score (Table 3).

\section{Fatigue}

Both severe bone pain and fatigue had a strong association with patient Fatigue score; an average increase of approximately 22 points in the Fatigue score was observed in patients with severe bone pain and those with moderate fatigue. Dizziness, sleepiness, nausea and/or vomiting, and a higher number of comorbidities were also associated with increased fatigue level. Patients whose current treatment regimen contained bortezomib, lenalidomide, or alkylating agents/other treatments reported, on average, an increase of $\geq 10$ points in their Fatigue score compared with patients not receiving treatment. General symptom level had no effect on the Fatigue score after individual AEs were included in the model (Table 3).

\section{Disease symptoms}

Patients with severe and moderate bone pain reported on average 38- and 18-point higher Disease Symptoms scores, respectively, compared with patients with mild or no bone pain. Muscle cramps were associated with an 11-point increase in Disease Symptoms score. Longer duration of current treatment and being male were associated with an increase in the Disease Symptoms score (Table 4). General symptom level had no effect on the Disease Symptoms score once individual AEs were included in the model.

\section{Future perspective}

Depression was associated with a 20-point reduction in the Future Perspective score. In addition, headache, sleepiness, German 
Table 3 Results of the multiple regression analyses: EORTC QLQ-C30 subscales (95\% confidence interval)

\begin{tabular}{|c|c|c|c|c|}
\hline Parameter & $\begin{array}{l}\text { Global Health } \\
\text { Status/QoL }\end{array}$ & Physical Functioning & Social Functioning & Fatigue \\
\hline \multicolumn{5}{|l|}{ Symptom group } \\
\hline Mildly symptomatic vs. asymptomatic & $-8.04(-19.42 ; 3.35)$ & $-11.44(-22.59 ;-0.29)^{*}$ & $-6.47(-22.46 ; 9.51)$ & NS \\
\hline Moderately symptomatic vs. asymptomatic & $-11.66(-23.93 ; 0.60)$ & $-13.47(-25.79 ;-1.16)^{*}$ & $-23.77(-40.05 ;-7.50)^{*}$ & NS \\
\hline Severely symptomatic vs. asymptomatic & $-19.11(-32.43 ;-5.79)^{*}$ & $-23.68(-37.30 ;-10.06)^{*}$ & $-33.95(-51.10 ;-16.80)^{*}$ & NS \\
\hline \multicolumn{5}{|l|}{ Bone pain } \\
\hline Moderate vs. mild/none & $N A^{b}$ & $-10.50(-20.04 ;-0.95)^{*}$ & NS & $\mathrm{NA}^{\mathrm{b}}$ \\
\hline Severe vs. mild/none & $\mathrm{NA}^{\mathrm{b}}$ & $-18.37(-32.26 ;-4.48)^{*}$ & NS & $\mathrm{NA}^{\mathrm{b}}$ \\
\hline Severe vs. moderate/mild/none & $-21.32(-34.69 ;-7.95)^{*}$ & NA & NS & $22.62(10.27 ; 34.98)^{*}$ \\
\hline Bone fracture: yes vs. no & NS & $-14.53(-25.87 ;-3.20)^{*}$ & $-15.06(-31.41 ; 1.28)$ & NS \\
\hline Fatigue (moderate vs. none/mild) & $-10.95(-19.64 ;-2.25)^{*}$ & $-14.00(-22.52 ;-5.49)^{*}$ & NS & $21.92(13.14 ; 30.70)^{*}$ \\
\hline Infection (moderate/severe vs. mild/none) & NS & $-21.54(-35.52 ;-7.55)^{*}$ & NS & NS \\
\hline Dizziness (yes vs. no) & NS & NS & $-15.13(-27.40 ;-2.86)^{*}$ & $11.75(1.99 ; 21.51)^{*}$ \\
\hline Depression (yes vs. no) & $-10.87(-20.65 ;-1.09)^{*}$ & NS & NS & NS \\
\hline Mental status changes (yes vs. no) & NS & NS & $-21.83(-45.50 ; 1.84)$ & NS \\
\hline Nausea/vomiting & NS & NS & NS & $14.91(3.64 ; 26.18)^{*}$ \\
\hline Sleepiness (yes vs. no) & NS & NS & NS & $9.51(1.43 ; 17.59)^{*}$ \\
\hline MM disease duration & $-0.95(-1.85 ;-0.05)^{*}$ & NS & NS & NS \\
\hline British descent & NS & $8.25(1.61 ; 14.89)^{*}$ & NS & NS \\
\hline Age & NS & $-0.50(-0.82 ;-0.18)^{*}$ & NS & NS \\
\hline Number of comorbidities & NS & NS & NS & $2.55(0.36 ; 4.73)^{*}$ \\
\hline Prior bortezomib ${ }^{\mathrm{a}}$ treatment duration & NS & $-0.09(-0.14 ;-0.04)^{*}$ & NS & NS \\
\hline Currently on treatment (yes vs. no) & $-9.49(-16.16 ;-2.83)^{*}$ & NS & NS & NS \\
\hline \multicolumn{5}{|l|}{ Type of current treatment } \\
\hline Bortezomib containing vs. none & NS & NS & NS & $10.56(1.80 ; 19.33)^{*}$ \\
\hline Lenalidomide containing vs. none & NS & NS & NS & $14.56(2.78 ; 26.34)^{*}$ \\
\hline Thalidomide containing vs. none & NS & NS & NS & $3.93(-8.66 ; 16.52)$ \\
\hline Alkylating agents containing/other vs. none & NS & NS & NS & $10.74(-3.23 ; 24.71)$ \\
\hline
\end{tabular}

$M M$ multiple myeloma, $Q o L$ quality of life, $N S$ not significant at 0.1 level (i.e., $P$ value of $>0.1$ ), $N A$ not applicable

$* P$ value of $<0.05$

${ }^{a}$ Prior thalidomide or alkylating agents were nonsignificant; prior lenalidomide and other treatments were not tested due to very low sample size $(n=3$ and $n=6$, respectively)

${ }^{\mathrm{b}}$ For Global Health Status and Fatigue, severity of bone pain was grouped into severe vs. moderate/mild/none given that there were no statistically significant differences between moderate, mild, and no bone pain on these scales. For Physical Functioning, severity of bone pain was grouped into severe, moderate, and mild/none given that there were no statitistically significant differences in effect on physical functioning between mild and no bone pain

descent, and receiving bortezomib- or lenalidomide-containing treatments (compared with no treatment) were all associated with $\geq 10$-point reduction in patients' Future Perspective scores. General symptom level had no effect on the Future Perspective score after depression, headache, and sleepiness were included in the model (Table 4).

\section{Discussion}

Our study demonstrates that both severity and type of disease symptoms, and treatment-related AEs are important determinants of HRQoL in patients with MM. Higher disease- and treatment-related symptom levels were associated with a lower Global Health Status/QoL and decreased Physical and Social Functioning. For patients with moderate and severe general symptoms, a reduction of 12 and 19 points in Global Health Status/QoL, 14 and 24 points in Physical Functioning, and 24 and 34 points in Social Functioning, respectively, were observed. In addition, we found that specific symptoms/AEs can impact patients' HRQoL above and beyond their general symptom level. Fatigue was one such symptom/AE associated with reduced Global Health Status/QoL and Physical Functioning, a finding that is in accordance with the limited data currently available on HRQoL in patients with MM [25]. Bone-related symptoms (i.e., pain and fracture) were also 
Table 4 Results of the multiple regression analyses: EORTC QLQ-MY20 subscales with (95\% confidence interval)

$N S$ not significant at 0.1 level (i.e., $P$ value of $>0.1$ ), $N A$ not applicable

$* P$ value of $<0.05$

\begin{tabular}{lll}
\hline Parameter & Disease Symptoms & Future Perspective \\
\hline Bone pain & & \\
$\quad$ Moderate vs. mild/none & $18.08(10.77 ; 25.38)^{*}$ & NS \\
$\quad$ Severe vs. mild/none & $37.54(27.77 ; 47.31)^{*}$ & NS \\
Depression (yes vs. no) & NS & $-20.11(-32.31 ;-7.92)^{*}$ \\
Sleepiness (yes vs. no) & NS & $-13.32(-22.14 ;-4.50)^{*}$ \\
Muscle cramps (mild/moderate vs. none) & $10.80(-0.71 ; 22.32)$ & NS \\
Headache (yes vs. no) & NS & $-13.25(-24.93 ;-1.57)^{*}$ \\
German descent & NS & $-11.82(-20.40 ;-3.23)^{*}$ \\
Sex (female vs. male) & $9.63(3.85 ; 15.41)^{*}$ & NS \\
Type of current treatment & & \\
$\quad$ Bortezomib containing vs. none & NS & $-10.13(-20.30 ; 0.04)$ \\
$\quad$ Lenalidomide containing vs. none & NS & $-11.63(-25.10 ; 1.85)$ \\
$\quad$ Thalidomide containing vs. none & NS & $0.64(-13.57 ; 14.85)$ \\
$\quad$ Alkylating agents containing/other vs. none & NS & $-6.33(-22.50 ; 9.85)$ \\
Duration of current treatment & $0.02(0.00 ; 0.03)$ & NS \\
\hline
\end{tabular}

important determinants that affected Global Health Status/ QoL, Physical and Social Functioning, Fatigue, and Disease Symptoms beyond general symptom levels. A previous study reported that in patients with certain types of malignancies, including myeloma, pathologic fractures correlate with reduced survival [26]. Depression was found to have a very strong negative association with the Future Perspective score. Moreover, mental status changes were associated with a reduction of almost 22 points in Social Functioning score. Similar findings have been reported in other studies [27, 28].

To our knowledge, this is the first study to assess the impact of general severity level of disease symptoms/AEs on patients' HRQoL and to examine whether specific symptoms/AEs affect the HRQoL of patients with MM more than others. The findings provide an insight for clinicians on how to better treat patients with MM to improve their QoL. These data underscore the need to better manage the treatment of symptoms associated with fatigue and bone-related symptoms because these are the strongest predictors of HRQoL. Our study also suggests that certain aspects of QoL such as Future Perspective, Disease Symptoms, and Fatigue can be improved significantly by targeted treatment of specific symptoms/AEs. Better psychological support aimed at preventing depression and other mental status changes can also greatly improve social functioning and patients' perception of the future, while better prevention of bone pain, nausea/vomiting, dizziness, and sleepiness can reduce fatigue levels in patients with MM.

Cancer patients experience a multitude of symptoms as a result of their disease and/or the treatments they receive. These symptoms often appear in clusters, which may suggest a common underlying cause. For example, the symptom cluster pain, fatigue, and sleep disorder is well established [29]. It has been shown that undertreated pain interrupts nighttime sleep but adequate pain control can reduce sleep problems [30]. Furthermore, fatigue intensity is strongly correlated with the efficiency of sleep and total sleep time [31]. This concept of symptom clustering underlines the importance of treating specific symptoms, such as pain, to improve the general symptom of global fatigue. Results from this study also highlight the need for the treating physicians to consider the overall sum of an MM therapy's clinical efficacy, its toxicity profile, and its effect on QoL when selecting an appropriate treatment strategy.

Our study does have some limitations. Treatment of any type was primarily expected to negatively affect HRQoL through related disease symptoms and AEs, with patients requiring treatment having more severe disease [31]. However, treatment remained a significant predictor in regression models for Physical Functioning, Fatigue, Disease Symptoms, and Future Perspective scales even after adjusting for disease symptoms and AEs. This suggests that some AEs/symptoms may have been underreported, leading to residual confounding in the effect of treatment on HRQoL. As an example, clinical evaluation has shown that as many as $75 \%$ of patients with MM may experience treatment-emergent peripheral neuropathy [32], whereas only $25 \%$ of patients reported it in our study. Another possibility relating to the significance of individual prior or current treatment variables (in the form of treatment status or type of treatment) is that these may have captured the effect of a multitude of AEs that, individually, were not significant in the multiple regression analyses. Given our limited sample size and rare reporting of some symptoms/ AEs, our analyses may have been underpowered to detect additional and potentially important symptoms/AEs, or additional groups of symptoms/AEs that impact patients' HRQoL. 


\section{Conclusions}

This study showed that, in addition to specific symptoms/AEs, the overall severity level is also an important predictor of patients' HRQoL. New treatment strategies should, therefore, focus not only on improving disease control and prolong survival but also contribute to optimal symptom management to improve, or at least maintain, patient QoL. Further studies should evaluate whether a specific, patient-focused symptom management program can positively affect QoL in patients receiving new MM treatment regimens. In addition, the assessment of the relationship between pretreatment disease status and treatment-emergent AEs is necessary to determine whether certain types of $\mathrm{AE}$ are associated with different Eastern Cooperative Oncology Group (ECOG) performance status.

Acknowledgments The authors received editorial assistance from Adriana Stan, $\mathrm{PhD}$, and Kathy Boon, $\mathrm{PhD}$, Excerpta Medica, sponsored by Celgene Corporation. This work was supported by Celgene Corporation in terms of investigator fees to the recruiting physicians and consultancy fees to United BioSource Corporation (UBC).

Conflicts of interest Irina Proskorovsky and Jack Ishak are employed by Evidera; Krista Payne and Noreen Lordan are employed by United BioSource Corporation, both companies provide consulting and other research services to pharmaceutical, device, government, and nongovernment organizations. In this salaried position, they work with a variety of companies and organizations; no payment or honoraria directly from these organizations for services rendered is received. Philip Lewis is employed by and holds stock options in Celgene, the manufacturer of Revlimid and thalidomide. Sarah Peters is employed by Celgene- consultancy. Faith E. Davies, Celgene: Speakers' Bureau; Janssen Cilag: Speakers' Bureau; Novartis: Speakers' Bureau; MSD: Speakers' Bureau. The remaining authors have declared no conflicts of interest.

Open Access This article is distributed under the terms of the Creative Commons Attribution Noncommercial License which permits any noncommercial use, distribution, and reproduction in any medium, provided the original author(s) and the source are credited.

\section{References}

1. Surveillance Epidemiology and End Results. National Cancer Institute. http://seer.cancer.gov/. Accessed 25 February 2013

2. Phekoo KJ, Schey SA, Richards MA, Bevan DH, Bell S, Gillett D, Møller H, Consultant Haematologists, South Thames Haematology Specialist Committee (2004) A population study to define the incidence and survival of multiple myeloma in a National Health Service Region in UK. Br J Haematol 127:299-304

3. International Agency for Research on Cancer. Cancer Mondial GLOBOCAN 2008 Database. http://www-dep.iarc.fr/. Accessed 25 February 2013

4. Kumar SK, Rajkumar SV, Dispenzieri A, Lacy MQ, Hayman SR, Buadi FK, Zeldenrust SR, Dingli D, Russell SJ, Lust JA, Greipp PR, Kyle RA, Gertz MA (2008) Improved survival in multiple myeloma and the impact of novel therapies. Blood 111:2516-2520

5. Palumbo A, Attal M, Roussel M (2011) Shifts in the therapeutic paradigm for patients newly diagnosed with multiple myeloma: maintenance therapy and overall survival. Clin Cancer Res 17: $1253-1263$

6. Larocca A, Palumbo A (2011) Evolving paradigms in the treatment of newly diagnosed multiple myeloma. J Natl Compr Canc Netw 9: 1186-1196

7. Dimopoulos M, Spencer A, Attal M, Prince HM, Harousseau JL, Dmoszynska A, San Miguel J, Hellmann A, Facon T, Foà R, Corso A, Masliak Z, Olesnyckyj M, Yu Z, Patin J, Zeldis JB, Knight RD, Multiple Myeloma (010) Study Investigators (2007) Lenalidomide plus dexamethasone for relapsed or refractory multiple myeloma. N Engl J Med 357:2123-2132

8. Dimopoulos MA, Chen C, Spencer A, Niesvizky R, Attal M, Stadtmauer EA, Petrucci MT, Yu Z, Olesnyckyj M, Zeldis JB, Knight RD, Weber DM (2009) Long-term follow-up on overall survival from the MM-009 and MM-010 phase III trials of lenalidomide plus dexamethasone in patients with relapsed or refractory multiple myeloma. Leukemia 23:2147-2152

9. Richardson PG, Sonneveld P, Schuster M, Irwin D, Stadtmauer E, Facon T, Harousseau JL, Ben-Yehuda D, Lonial S, Goldschmidt H, Reece D, Miguel JS, Bladé J, Boccadoro M, Cavenagh J, Alsina M, Rajkumar SV, Lacy M, Jakubowiak A, Dalton W, Boral A, Esseltine DL, Schenkein D, Anderson KC (2007) Extended follow-up of a phase 3 trial in relapsed multiple myeloma: final time-to-event results of the APEX trial. Blood 110:3557-3560

10. Richardson PG, Sonneveld P, Schuster MW, Irwin D, Stadtmauer EA, Facon T, Harousseau JL, Ben-Yehuda D, Lonial S, Goldschmidt H, Reece D, San-Miguel JF, Bladé J, Boccadoro M, Cavenagh J, Dalton WS, Boral AL, Esseltine DL, Porter JB, Schenkein D, Anderson KC, Assessment of Proteasome Inhibition for Extending Remissions (APEX) Investigators (2005) Bortezomib or high-dose dexamethasone for relapsed multiple myeloma. N Engl J Med 352: 2487-2498

11. Weber DM, Chen C, Niesvizky R, Wang M, Belch A, Stadtmauer EA, Siegel D, Borrello I, Rajkumar SV, Chanan-Khan AA, Lonial S, Yu Z, Patin J, Olesnyckyj M, Zeldis JB, Knight RD, Multiple Myeloma (009) Study Investigators (2007) Lenalidomide plus dexamethasone for relapsed multiple myeloma in North America. N Engl J Med 357:2133-2142

12. Facon T, Mary JY, Hulin C, Benboubker L, Attal M, Pegourie B, Renaud M, Harousseau JL, Guillerm G, Chaleteix C, Dib M, Voillat L, Maisonneuve H, Troncy J, Dorvaux V, Monconduit M, Martin C, Casassus P, Jaubert J, Jardel H, Doyen C, Kolb B, Anglaret B, Grosbois B, Yakoub-Agha I, Mathiot C, Avet-Loiseau H, Intergroupe Francophone du Myélome (2007) Melphalan and prednisone plus thalidomide versus melphalan and prednisone alone or reduced-intensity autologous stem cell transplantation in elderly patients with multiple myeloma (IFM 99-06): a randomised trial. Lancet 370:1209-1218

13. Hulin C, Facon T, Rodon P, Pegourie B, Benboubker L, Doyen C, Dib M, Guillerm G, Salles B, Eschard JP, Lenain P, Casassus P, Azaïs I, Decaux O, Garderet L, Mathiot C, Fontan J, Lafon I, Virion JM, Moreau P (2009) Efficacy of melphalan and prednisone plus thalidomide in patients older than 75 years with newly diagnosed multiple myeloma: IFM 01/01 trial. J Clin Oncol 27:3664-3670

14. Mateos MV, Richardson PG, Schlag R, Khuageva NK, Dimopoulos MA, Shpilberg O, Kropff M, Spicka I, Petrucci MT, Palumbo A, Samoilova OS, Dmoszynska A, Abdulkadyrov KM, Schots R, Jiang B, Esseltine DL, Liu K, Cakana A, van de Velde H, San Miguel JF (2010) Bortezomib plus melphalan and prednisone compared with melphalan and prednisone in previously untreated multiple myeloma: updated follow-up and impact of subsequent therapy in the phase III VISTA trial. J Clin Oncol 28:2259-2266

15. San Miguel JF, Schlag R, Khuageva NK, Dimopoulos MA, Shpilberg O, Kropff M, Spicka I, Petrucci MT, Palumbo A, Samoilova OS, Dmoszynska A, Abdulkadyrov KM, Schots R, Jiang B, Mateos MV, Anderson KC, Esseltine DL, Liu K, Cakana A, van de Velde H, Richardson PG, VISTA Trial Investigators (2008) 
Bortezomib plus melphalan and prednisone for initial treatment of multiple myeloma. N Engl J Med 359:906-917

16. Moreau P, Pylypenko H, Grosicki S, Karamanesht I, Leleu X, Grishunina M, Rekhtman G, Masliak Z, Robak T, Shubina A, Arnulf B, Kropff M, Cavet J, Esseltine DL, Feng H, Girgis S, van de Velde H, Deraedt W, Harousseau JL (2011) Subcutaneous versus intravenous administration of bortezomib in patients with relapsed multiple myeloma: a randomised, phase 3 , non-inferiority study. Lancet Oncol 12:431-440

17. Farquhar-Smith $P$ (2011) Chemotherapy-induced neuropathic pain. Curr Opin Support Palliat Care 5:1-7

18. Durie BG (2005) New approaches to treatment for multiple myeloma: durable remission and quality of life as primary goals. Clin Lymphoma Myeloma 6:181-190

19. Wisløff F, Gulbrandsen N (2000) Health-related quality of life and patients' perceptions in interferon-treated multiple myeloma patients. Nordic Myeloma Study Group. Acta Oncol 39:809-813

20. Uyl-de Groot CA, Buijt I, Gloudemans IJ, Ossenkoppele GJ, Berg HP, Huijgens PC (2005) Health related quality of life in patients with multiple myeloma undergoing a double transplantation. Eur $\mathrm{J}$ Haematol 74:136-143

21. Cocks K, Cohen D, Wisløff F, Sezer O, Lee S, Hippe E, Gimsing P, Turesson I, Hajek R, Smith A, Graham L, Phillips A, Stead M, Velikova G, Brown J, EORTC Quality of Life Group (2007) An international field study of the reliability and validity of a diseasespecific questionnaire module (the QLQ-MY20) in assessing the quality of life of patients with multiple myeloma. Eur J Cancer 43: $1670-1678$

22. Kvam AK, Fayers P, Wisloff F (2010) What changes in health-related quality of life matter to multiple myeloma patients? A prospective study. Eur J Haematol 84:345-353

23. Williams CD, Proskorovsky I, Lewis P, Ishak KJ, Payne KA, Lordan N, Kyriakou C, Davies F, Peters S, Jordan K (2010) Components of Global Quality of Life in multiple myeloma [abstract]. Blood 116:4735
24. Fayers P, Aaronson N, Bjordal K, Groenvold M, Curran D, Bottomley A (2001) The EORTC QLQ-C30 Scoring Manual, 3rd edn. EORTC Quality of Life Group, Brussels

25. Molassiotis A, Wilson B, Blair S, Howe T, Cavet J (2011) Unmet supportive care needs, psychological well-being and quality of life in patients living with multiple myeloma and their partners. Psychooncology 20:88-97

26. Saad F, Lipton A, Cook R, Chen YM, Smith M, Coleman R (2007) Pathologic fractures correlate with reduced survival in patients with malignant bone disease. Cancer 110:1860-1867

27. Lee SJ (2004) Patient-reported outcomes in multiple myeloma. J Natl Compr Canc Netw 2:379-383

28. Poulos AR, Gertz MA, Pankratz VS, Post-White J (2001) Pain, mood disturbance, and quality of life in patients with multiple myeloma. Oncol Nurs Forum 28:1163-1171

29. Kirkova J, Walsh D, Aktas A, Davis MP (2010) Cancer symptom clusters: old concept but new data. Am J Hosp Palliat Care 27:282-288

30. Cheng KK, Lee DT (2011) Effects of pain, fatigue, insomnia, and mood disturbance on functional status and quality of life of elderly patients with cancer. Crit Rev Oncol Hematol 78:127-137

31. Delforge M, Dhawan R, Robinson D Jr, Meunier J, Regnault A, Esseltine DL, Cakana A, van de Velde H, Richardson PG, San Miguel JF (2012) Health-related quality of life in elderly, newly diagnosed multiple myeloma patients treated with VMP vs. MP: results from the VISTA trial. Eur J Haematol 89:16-27

32. Richardson PG, Delforge M, Beksac M, Wen P, Jongen JL, Sezer O, Terpos E, Munshi N, Palumbo A, Rajkumar SV, Harousseau JL, Moreau P, Avet-Loiseau H, Lee JH, Cavo M, Merlini G, Voorhees P, Chng WJ, Mazumder A, Usmani S, Einsele H, Comenzo R, Orlowski R, Vesole D, Lahuerta JJ, Niesvizky R, Siegel D, Mateos MV, Dimopoulos M, Lonial S, Jagannath S, Bladé J, Miguel JS, Morgan G, Anderson KC, Durie BG, Sonneveld P (2012) Management of treatment-emergent peripheral neuropathy in multiple myeloma. Leukemia 26:595-608 